sion: effect of electrode position on efficacy [Abstract]. Clin Res 1986;34:341A.

11. Schuder JC, Gold JH, Stoeckle M, McDaniel WC, Cheung KN. Transthoracic ventricular defibrillation in the $100 \mathrm{~kg}$ calf with symmetrical one-cycle bidirectional rectangular wave stimuli. IEEE Trans Biomed Eng 1983;30:415-22.

12. Tang AS, Yabe S, Wharton JM, Dolker M, Smith WM, Ideker RE. Ventricular defibrillation using biphasic waveforms: the importance of phasic duration. J Am Coll Cardiol 1989;13:20714.

13. Jones JL, Jones RE. Decreased defibrillator-induced dysfunction with biphasic rectangular waveforms. Am J Physiol 1984;247:H792-6.

14. Winkle RA, Mead RH, Ruder MA, Gandiani V, Buch WS Pless B, Sweeney $M$, Schmidt $P$. Improved low energy defibrillation efficacy in man with the use of biphasic truncated exponential waveform. AM HEART J 1989;117:122-7.

15. Holmes DR, Holmes DR Jr. Pacemaker implantation tech- niques. In: Saksena S, Goldschlager N, eds. Electrical therapy for cardiac arrhythmias. Philadelphia: WB Saunders Co, 1990:173-90.

16. Timmis GC. The electrobiology and engineering of pacemaker leads. In: Saksena S, Goldschlager N, eds. Electrical therapy for cardiac arrhythmias. Philidelphia: WB Saunders Co, 1990:35-90.

17. Van Vleet JF, Tacker WA Jr, Bourland JD, Kallok MJ, Schollmeyer MP. Cardiac damage in dogs with chronically implanted automatic defibrillator electrode catheters and given four episodes of multiple shocks. AM HEART J 1983; 106:300-7.

18. Waspe LE, Kim SG, Matos JA, Fisher JD. Role of a catheter lead system for transvenous countershock and pacing during electrophysiologic tests: an assessment of the usefulness of catheter shocks for terminating ventricular tachyarrhythmias. Am J Cardiol 1983;52:477-84.

\title{
The role of $\beta$-blockade therapy for ventricular tachycardia induced with isoproterenol: A
} prospective analysis

\begin{abstract}
Isoproterenol is sometimes required for ventricular tachycardia (VT) induction. However, the role of $\beta$-blockade for treatment of such VT has not been critically assessed. The use of $\beta$-blockade was evaluated prospectively in 14 consecutive patients who required isoproterenol $2.4 \pm 1.3$ ( \pm S. D.) $\mu \mathrm{g} / \mathrm{min}$ to induce sustained monomorphic VT $(>30$ seconds, or requiring termination due to hemodynamic collapse) after a negative baseline study. The VT mechanisms were enhanced automaticity (group A, six patients), triggered automaticity (group B, three patients), and reentry (group C, five patients). Groups A and B had serial intravenous electropharmacologic tests with propranolol alone $(0.2 \mathrm{mg} / \mathrm{kg})$, verapamil alone $(0.15 \mathrm{mg} / \mathrm{kg})$, and propranolol plus verapamil, and group $\mathrm{C}$ had serial tests with propranolol alone, procainamide or quinidine (class la drug) alone, and propranolol plus a class la drug until VT could no longer be induced. All six patients in group A responded to propranolol alone. In group B, one patient responded to verapamil alone, and two patients responded to propranolol plus verapamil. In group $C$, three patients responded to propranolol alone, one patient responded to a class la drug alone, and one patient responded to propranolol plus a class la drug. During a follow-up of 7 to $37(17.9 \pm 10.7)( \pm S$. D.) months, VT has not recurred in any patient. Three patients treated initially with propranolol alone have required substitution of amiodarone due to refractory congestive heart fallure. In patients requiring isoproterenol for VT induction, $\beta$-blockade alone appears to be effective in preventing reinduction of VT caused by enhanced automaticity. A heterogeneous response occurs when the VT mechanisms are triggered automaticity or reentry. (AM HEART J 1990; 120:1347.)
\end{abstract}

Lorenzo A. DiCarlo, Jr., MD, Frank Susser, DO, and Stuart A. Winston, DO. Ann Arbor, Mich.

From the Cardiac Electrophysiology Laboratory, St. Joseph Mercy Hospital of the Catherine McAuley Health Center, and the School of Medicine, University of Michigan.

Received for publication May 21, 1990; accepted July 9, 1990.

Reprint requests: Lorenzo A. DiCarlo, MD, Reichert Health Building, R-3003, P.o. Box 994, Ann Arbor, MI 48106.

4/1/24130
Patients with recurrent, sustained monomorphic ventricular tachycardia (VT) sometimes require intravenous administration of $\beta$-agonists such as isoproterenol for initiation of ventricular tachycardia in the cardiac electrophysiology laboratory. ${ }^{1-6}$ Traditionally, selection of appropriate antiarrhythmic 
Table I. Patient characteristics and results

\begin{tabular}{|c|c|c|c|c|c|c|c|c|c|c|c|c|}
\hline \multirow{2}{*}{$\begin{array}{l}\text { Patient } \\
\text { No. }\end{array}$} & \multirow{2}{*}{$\begin{array}{l}\text { Age }(y r) \\
\quad / \text { sex }\end{array}$} & \multirow{2}{*}{$\begin{array}{c}\text { Heart } \\
\text { disease }\end{array}$} & \multicolumn{3}{|c|}{$S C L$ (msec) } & \multicolumn{2}{|c|}{$V T$} & \multirow[b]{2}{*}{ Initiation } & \multirow[b]{2}{*}{ Mechanism } & \multirow{2}{*}{$\begin{array}{c}\text { Effective } \\
A A(E P T)\end{array}$} & \multirow{2}{*}{$\begin{array}{c}\text { Long-term } \\
\text { AA }\end{array}$} & \multirow{2}{*}{$\begin{array}{l}F / U \\
(m o)\end{array}$} \\
\hline & & & Rest & Iso & Iso $/ P$ & Morphology & $C L$ (msec) & & & & & \\
\hline 1 & $80 / \mathrm{M}$ & RHD & 1160 & 620 & 890 & RBB-I & 350 & Spont & EA & $\mathrm{P}$ & Amio & 37 \\
\hline 2 & $44 / \mathrm{F}$ & $\mathrm{CAD}$ & 740 & 480 & 810 & RBB-S & 420 & Spont & EA & $\mathrm{P}$ & Amis & .33 \\
\hline 3 & $58 / \mathrm{F}$ & MVP & 790 & 550 & 750 & IND-I & 280 & Spont & EA & $\mathrm{P}$ & $\mathrm{Nad}$ & 25 \\
\hline 4 & $44 / \mathrm{F}$ & MVP & 810 & 420 & 750 & LBB-I & 290 & Spont & EA & $\mathrm{P}$ & Aten & 21 \\
\hline 5 & $42 / \mathrm{F}$ & RVD & 980 & 530 & 930 & LBB-I & 290 & Spont & EA & $\mathrm{P}$ & $\mathrm{Nad}$ & 11 \\
\hline 6 & $24 / \mathrm{F}$ & RVD & 925 & 810 & 810 & LBB-I & 260 & Spont & $\mathrm{EA}$ & $\mathrm{P}$ & Aten & 7 \\
\hline 7 & $32 / \mathrm{F}$ & MVP & 860 & 430 & 820 & RBB-I & 290 & PVS (3) & $\mathrm{R}$ & $\mathrm{P}$ & $\mathrm{P}$ & 28 \\
\hline 8 & $62 / \mathrm{M}$ & $\mathrm{CAD}$ & 1000 & 800 & 930 & RBB-I & 290 & PVS (3) & $\mathrm{R}$ & $\mathrm{P}$ & Amio & 19 \\
\hline 9 & $24 / \mathrm{M}$ & RVD & 760 & 490 & 800 & RBB-S & 260 & PVS (2) & $\mathrm{R}$ & $\mathrm{P}$ & Aten & 5 \\
\hline 10 & $62 / \mathrm{F}$ & HTN & 580 & 410 & 1060 & LBB-S & 270 & PVS (3) & $\mathrm{R}$ & $P, Q$ & Aten, Q & 5 \\
\hline 11 & $46 / \mathrm{M}$ & $\mathrm{CAD}$ & 830 & 750 & 970 & LBB-I & 260 & PVS (1) & $\mathrm{R}$ & Proc & Proc & 8 \\
\hline 12 & $14 / \mathrm{F}$ & RVD & 680 & 520 & 670 & LBB-S & 340 & $\mathrm{OP}$ & $\mathrm{TA}$ & $P, V$ & $P, V$ & 23 \\
\hline 13 & $84 / \mathrm{M}$ & None & 780 & 530 & 920 & RBB-I & 370 & OP,PVS $(1,2)$ & $\mathrm{TA}$ & $\mathrm{P}, \mathrm{V}$ & $P, V$ & 21 \\
\hline 14 & $78 / \mathrm{F}$ & None & 810 & 580 & 910 & LBB-I & 300 & $\mathrm{OP}$ & TA & $\mathrm{V}$ & $\mathrm{V}$ & 8 \\
\hline
\end{tabular}

Amio, Amiodarone; Aten, atenolol; AA, antiarrhythmic agent; CAD, coronary artery disease; CL, cycle length: EA, enhanced automaticity; EPT, electropharmacologic testing; F/U, follow-up; -I, inferior axis; HTN, hypertension; IND, indetereminate; Iso, isoproterenol; Iso/P, isoproterenol + propranolol; LBB, left bundle branch configuration; MVP, mitral valve prolapse; Nad, nadolol; OP, overdrive pacing; P. propranolol; Proc, procainamide: PVS, programmed ventricular stimulation; $Q$, quinidine; $R$, reentry; $R B B$, right bundle branch configuration; $R H D$, rheumatic heart disease; $R V D$, right ventricular dysplasia; $-\mathrm{S}$, superior axis; SCL, sinus cycle length; Spont, spontaneous; TA, triggered automaticity; V, verapamil; VT, ventricular tachycardia; Numbers in parentheses, number of ventricular extrastimuli.

therapy for the induced VT has been based upon the VT mechanism. ${ }^{5,6}$ To date, a critical assessment of the role of $\beta$-blockade in the treatment of such dysrhythmias has not been undertaken. In this prospective study, the role of $\beta$-blockade therapy was evaluated in consecutive patients who required isoproterenol for initiation of VT after a negative baseline cardiac electrophysiology study.

\section{METHODS}

Patient population. Fourteen patients with recurrent, sustained monomorphic ventricular tachycardia were evaluated (Table I). There were five males and nine females, with an age range of 14 to 78 years. Three patients had coronary artery disease with a history of myocardial infarction, four patients had valvular heart disease, three patients had right ventricular dysplasia, one patient had hypertensive heart disease, and three patients had no clinical evidence of structural heart disease. Three patients had VT associated with physical exertion, and one patient had VT occur during extreme emotional distress.

Electrophysiology study protocol. Patients were studied in the postoperative, fasting state after discontinuation of antiarrhythmic therapy for at least 5 half-lives. Midazolam, 1 to $3 \mathrm{mg}$, was used intravenously for sedation. Three $6 \mathrm{~F}$ quadripolar electrode catheters were inserted percutaneously into the right femoral vein and were positioned under fluoroscopic guidance against the high right atrium, the right ventricular apex, and across the tricuspid valve to record a His bundle potential. Surface electrocardiographic leads $\mathrm{V}_{1}, \mathrm{I}, \mathrm{III}$, and intracardiac electrograms were recorded on a Siemens-Elema Mingograf recorder (Siemens Elema AB, Solna, Sweden) at paper speeds of 25 to 100 $\mathrm{mm} / \mathrm{sec}$. A 12-lead electrocardiogram was also recorded whenever sustained monomorphic VT was initiated.

Stimulation was performed with a programmable stimulator (Bloom Associates, Ltd., Narberth, Pa.), with stimuli having a pulse width of $2 \mathrm{msec}$ and a current twice diastolic threshold. Atrial overdrive pacing was performed initially, beginning at a cycle length of $50 \mathrm{msec}$ less than the spontaneous sinus cycle length and decreasing in $50 \mathrm{msec}$ intervals to a minimum of 250 to $270 \mathrm{msec}$. Atrial programmed stimulation with one and two atrial extrastimuli was performed using an atrial drive cycle length at least 200 msec greater than the atrial cycle length that caused Wenkebach periodicity. Ventricular programmed stimulation was performed initially at the right ventricular apex. A similar protocol was performed at the right ventricular outflow tract if VT could not be initiated. Six to eight cycle drive trains were used with drive cycle lengths $\left(S_{1} S_{1}\right)$ of 600 and 500 or $400 \mathrm{msec}$. The inter-train interval was 3 seconds. The coupling interval of the first extrastimulus $\left(\mathrm{S}_{1} \mathrm{~S}_{2}\right)$ was initially 520,420 , or 320 msec, respectively. $S_{1} S_{2}$ was decreased in intervals of 10 msec until refractoriness to $S_{2}$ occurred. $\mathrm{S}_{1} \mathrm{~S}_{2}$ was increased by $30 \mathrm{msec}$, and a second extrastimulus $\left(\mathrm{S}_{2} \mathrm{~S}_{3}\right)$ was initiated with an interval that was 300 msec greater than $S_{1} S_{2} . S_{2} S_{3}$ was decreased in $10 \mathrm{msec}$ intervals until refractoriness to $S_{3}$ occurred, and was then increased by 20 to $30 \mathrm{msec} . \mathrm{S}_{1} \mathrm{~S}_{2}$ was then decreased again in $10 \mathrm{msec}$ intervals until refractoriness of $S_{2}$ occurred. After stimulation with $S_{2}$ and $S_{3}$ was completed with two drive cycle lengths, $S_{1} S_{2}$ and $S_{2} S_{3}$ were increased to $30 \mathrm{msec}$ more than the effective refractory periods of $S_{2}$ and $S_{3}$, respectively, and programmed stimulation was continued using a third extrastimulus $\left(\mathbf{S}_{3} \mathbf{S}_{4}\right)$ that was $300 \mathrm{msec}$ greater than $S_{2} S_{3}$. $S_{3} S_{4}$ was decreased in 10 msec intervals 


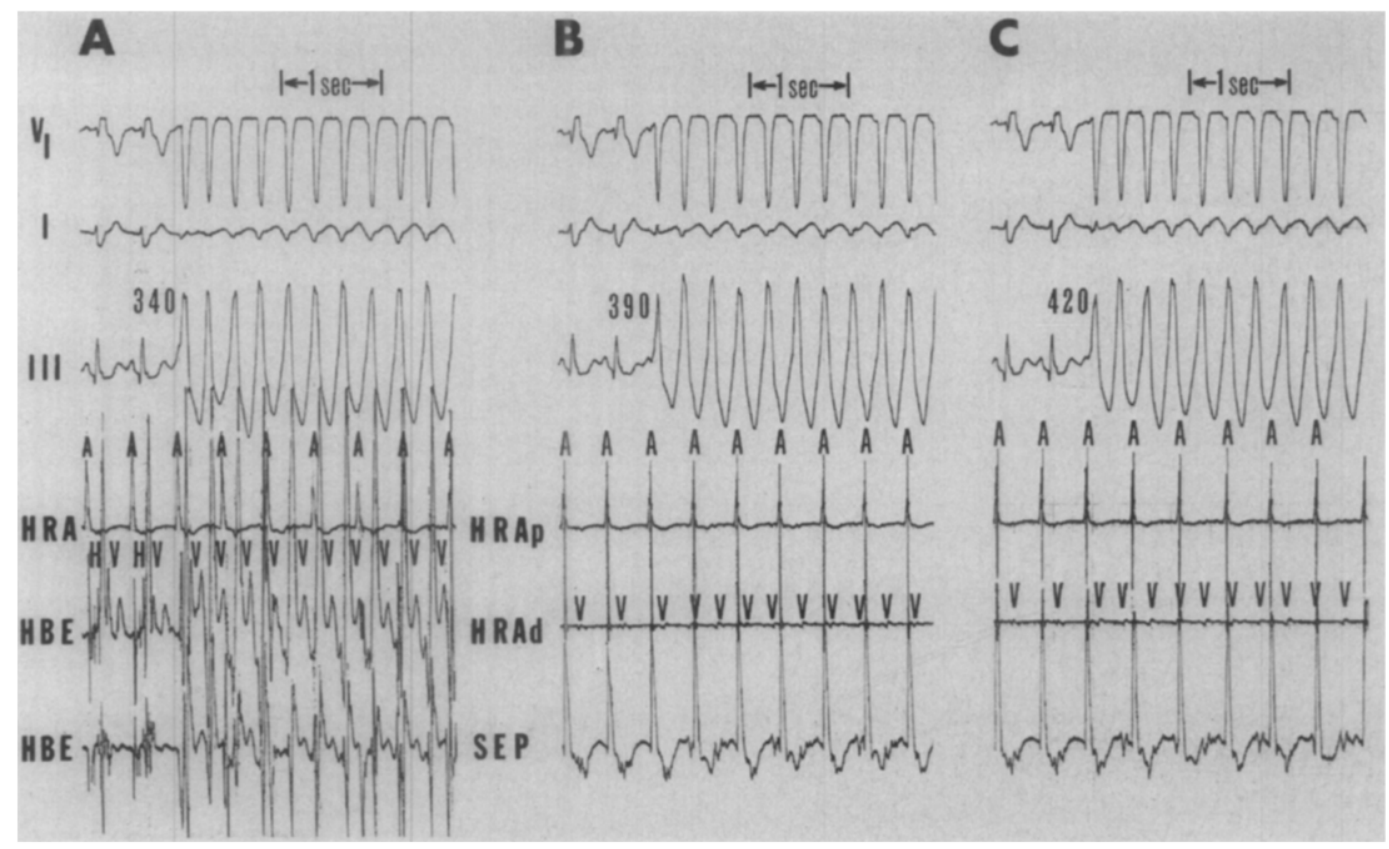

Fig. 1. Sustained ventricular tachycardia (VT) occurred spontaneously in this patient (No. 3) with enhanced automaticity during continuous intravenous isoproterenol administration. The coupling interval between the last sinus rhythm QRS and the first VT QRS varied from 340 to $420 \mathrm{msec}$ (panels A, B, and C). After intravenous administration of propranolol, this VT did not recur spontaneously when isoproterenol was readministered nor could it be induced by programmed ventricular stimulation or ventricular overdrive pacing. Shown are a one-second $(1 \mathrm{sec})$ time-line, surface electrocardiographic leads V1, I, and III, and intracardiac recordings of atrial $(A)$, ventricular $(V)$, and His bundle $(H)$ activation from the proximal $(p)$ and distal $(d)$ high right atrium $(H R A)$, His bundle electrogram $(H B E)$, and atrial septum (SEP).

until refractoriness to $\mathrm{S}_{4}$ occurred. $\mathrm{S}_{3} \mathrm{~S}_{4}$ was then increased by 20 to $30 \mathrm{msec}$, and $\mathrm{S}_{2} \mathrm{~S}_{3}$ was decreased in $10 \mathrm{msec}$ intervals until refractoriness to $S_{3}$ occurred. After $S_{2} S_{3}$ was increased again by $30 \mathrm{msec}, \mathrm{S}_{1} \mathrm{~S}_{2}$ was decreased in $10 \mathrm{msec}$ intervals until refractoriness to $S_{2}$ occurred. After completion of programmed stimulation with $\mathrm{S}_{3} \mathrm{~S}_{4}$ using two drive cycle lengths, ventricular burst pacing was performed using drive cycle lengths of 600 to $260 \mathrm{msec}$ with drive trains of 15 cycles. The drive cycle length was decreased by 20 msec after each train was delivered. The inter-train interval was 3 seconds. Programmed stimulation at the right ventricular outflow tract was performed after completion of the protocol at the right ventricular apex.

Infusion of isoproterenol. After completion of programmed stimulation, isoproterenol was infused at rates of 0.5 to $4.0 \mu \mathrm{g} / \mathrm{min}$ (mean $\pm \mathrm{S}$. D. $=2.4 \pm 1.3 \mu \mathrm{g} / \mathrm{min}$ ). The spontaneous sinus cycle length decreased by $32 \pm 13 \%$. If VT did not occur spontaneously during isoproterenol administration, programmed stimulation was repeated at both right ventricular sites, as previously described.

Definitions of mechanisms of induced ventricular tachycardia. The following principles of clinical electrophysiology were utilized to classify the mechanisms of the induced VTs. ${ }^{7}$

Enhanced automaticity (group A). VT could not be induced by programmed stimulation but occurred spontaneously during isoproterenol infusion with varying coupling intervals between the last sinus rhythm QRS complex and the initial VT QRS complex. The initial VT QRS complex had the same morphology as the monomorphic VT. The VT could not be converted to sinus rhythm by overdrive pacing or programmed stimulation, and the VT morphology and cycle length did not change after overdrive pacing. Advancement of the first post-pacing VT QRS complex did not occur after overdrive pacing. The VT resolved only with discontinuation of isoproterenol.

Triggered automaticity (group B). VT could be initiated consistently over a specific range of cycle lengths during burst ventricular pacing without ventricular extrastimuli. The VT cycle length varied with the burst pacing cycle length. The first VT QRS complex occurred late in the cardiac cycle. This VT could be terminated by burst ventricular pacing.

Reentry (group $C$ ). VT was initiated with ventricular extrastimuli and could be terminated by overdrive pacing. Advancement of the first post-pacing VT QRS complex was sometimes observed when burst pacing or programmed extrastimuli failed to successfully terminate the induced VT.

\section{Electropharmacologic testing}

Groups $A$ and B. During initial electropharmacologic testing, propranolol, $0.2 \mathrm{mg} / \mathrm{kg}$, was administered intravenously and repeat testing was performed using the same dose of isoproterenol required to induce VT during the 


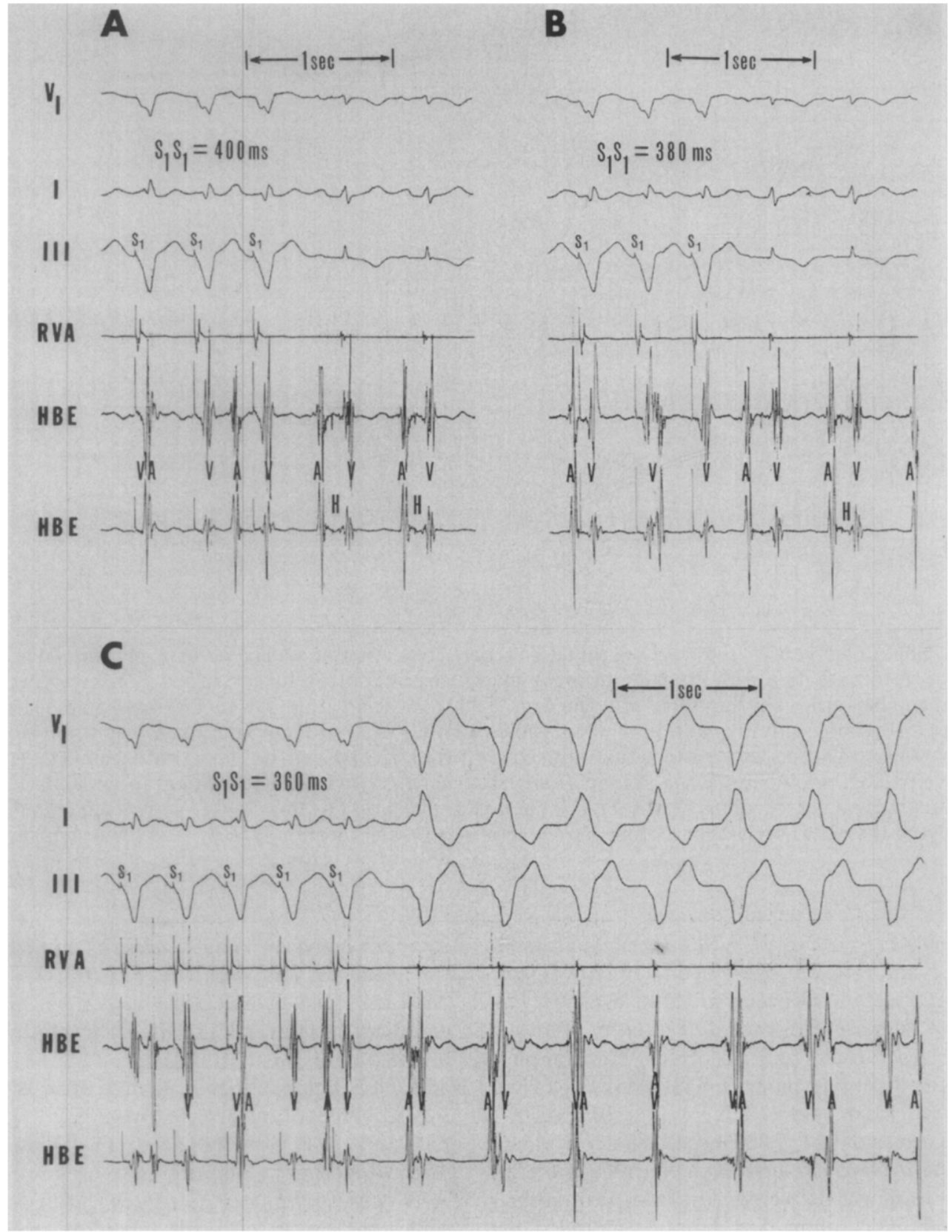

Fig. 2. A through C. In this patient (No. 12) with triggered automaticity, sustained VT could be induced only by ventricular overdrive pacing during isoproterenol administration. VT was consistently induced by ventricular overdrive pacing at cycle lengths $\left(S_{1} S_{1}\right)$ of 340 and $360 \mathrm{msec}$ (panels $C$ and D), but not at cycle lengths greater than $380 \mathrm{msec}$ (panels $\mathbf{A}$ and $\mathbf{B}$ ) or less than $320 \mathrm{msec}$ (panels $\mathbf{E}$ and F). This VT was not suppressed with intravenous propranolol alone or verapamil alone, but was suppressed with combined therapy with propranolol and verapamil. Ventricular electrograms from the right ventricular apex $(R V A)$ are shown. Other abbreviations are the same as in Fig. 1.

baseline study. If propranolol alone did not suppress reinduction of VT, electropharmacologic testing was repeated after a minimum of 48 hours using an intravenous dose of verapamil alone $(0.15 \mathrm{mg} / \mathrm{kg})$. If verapamil alone did not suppress reinduction of VT, propranolol was administered in doses of 0.1 to $0.2 \mathrm{mg} / \mathrm{kg}$, depend- ing upon heart rate and blood pressure response, and testing was repeated.

Group C. Initial electropharmacologic testing of propranolol was performed in a manner similar to that for groups $A$ and $B$. If propranolol alone did not suppress reinduction of VT, electropharmacologic testing was repeated after a 


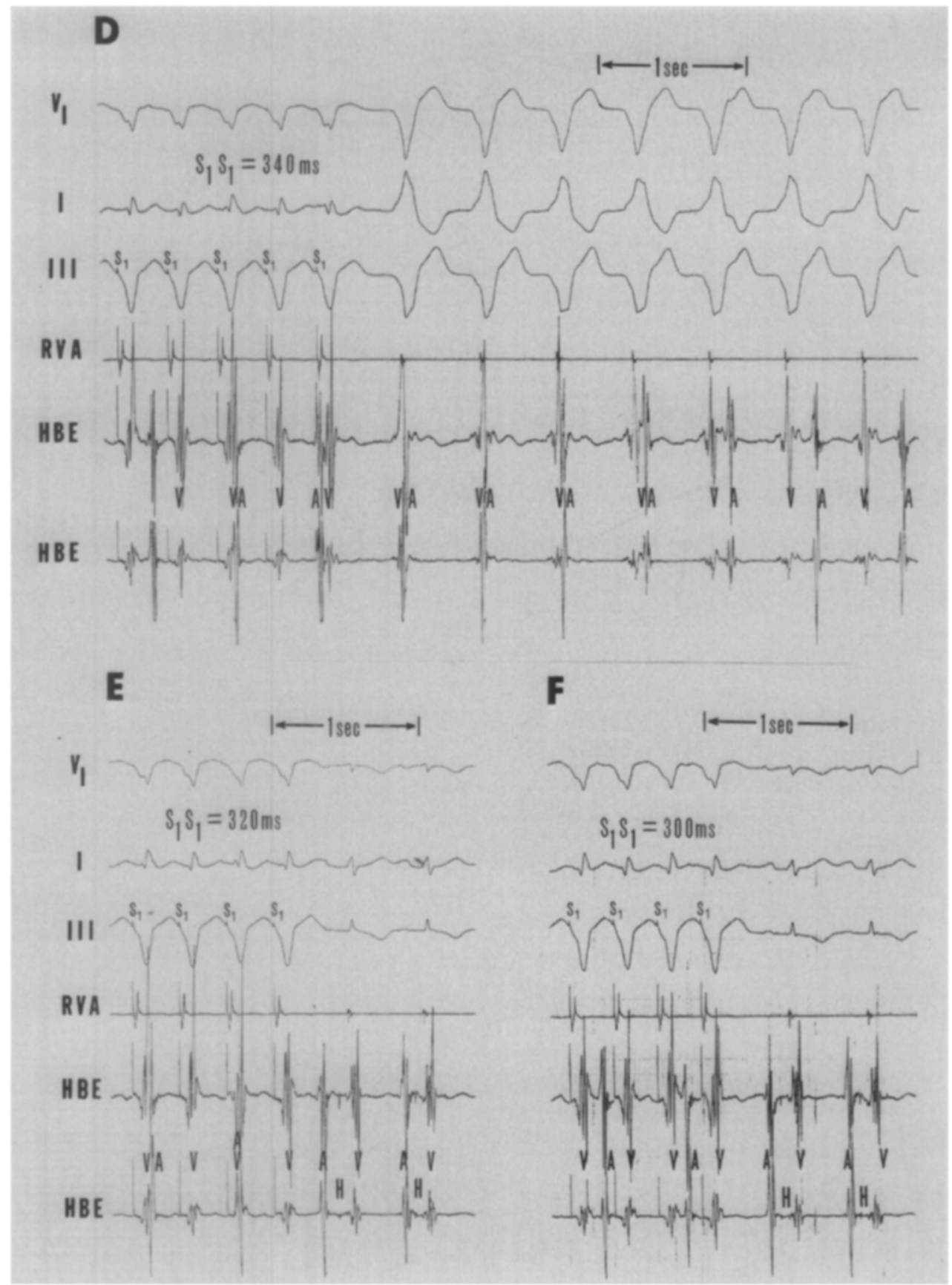

Fig. 2, D through F. For explanation, see legend to Fig. 2, $A$ through $C$.

minimum of 48 hours with intravenously administered procainamide or quinidine $(10 \mathrm{mg} / \mathrm{kg}$ load and 0.06 to 0.075 $\mathrm{mg} / \mathrm{kg} / \mathrm{min}$ ). If the class Ia drug did not suppress reinduction of VT, propranolol was readministered in a dose of 0.2 $\mathrm{mg} / \mathrm{kg}$ and electropharmacologic testing was repeated.

All patients underwent final testing of orally administered drugs before hospital discharge to confirm that VT was not inducible using the previously described protocol before and during isoproterenol administration.

Follow-up. All patients were followed as outpatients with office visits every 2 to 3 months for the first 6 months, and with office visits or telephone contact every 3 months thereafter.

\section{RESULTS}

The results of electrophysiologic and electropharmacologic testing are summarized in Table I. All 14 patients required intravenous isoproterenol administration to induce sustained VT. Sustained mono- 


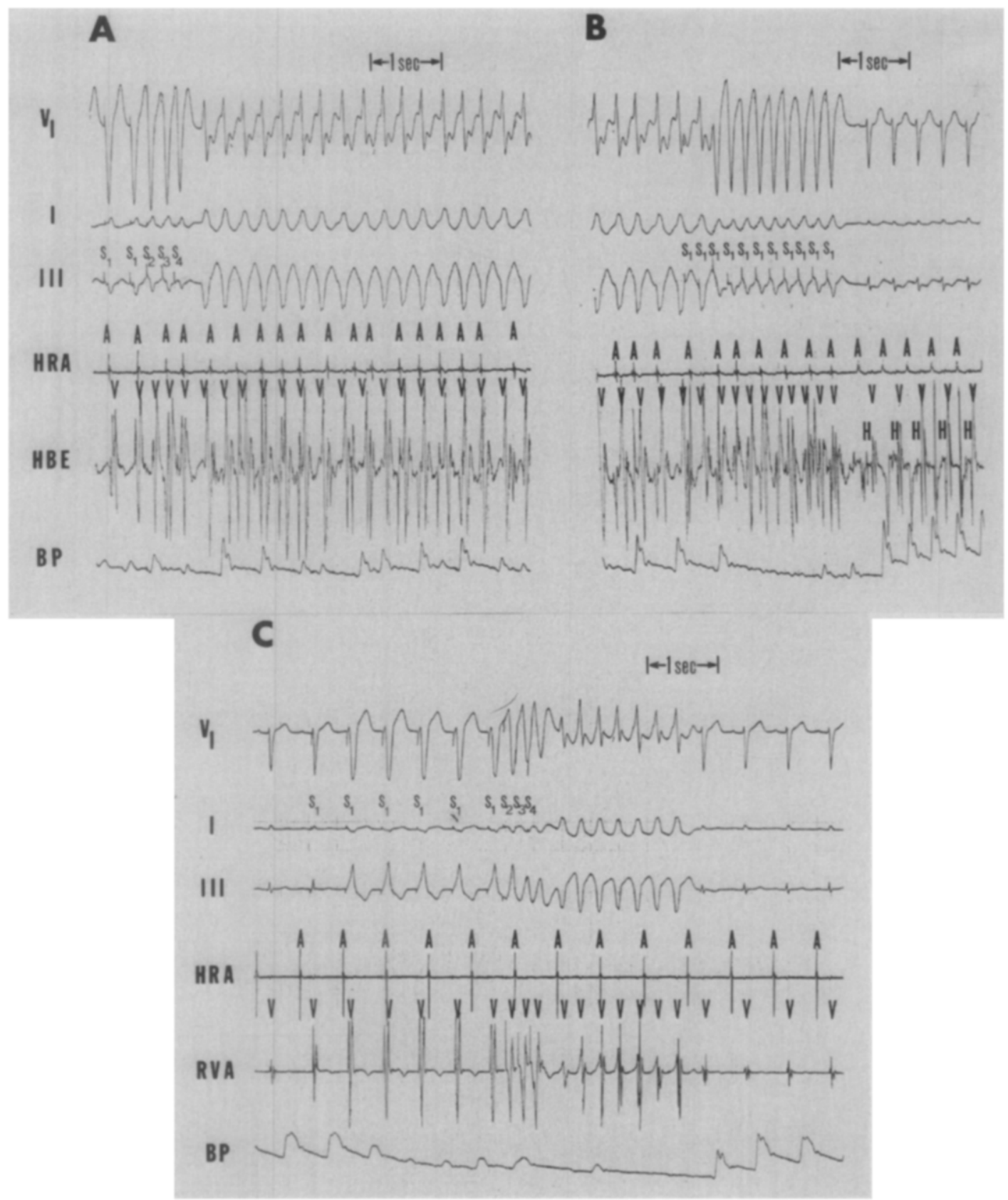

Fig. 3. Initiation of sustained VT during isoproterenol administration in this patient (No. 10) with reentry consistently required three ventricular extrastimuli $\left(\mathrm{S}_{2} \mathrm{~S}_{3} \mathrm{~S}_{4}\right)$ during programmed ventricular stimulation (panel A), and was associated with a fall in blood pressure (BP). Ventricular overdrive pacing $\left(S_{1} S_{1}\right)$ was uniformly successful in terminating this VT (panel B). Reinduction of this VT could not be suppressed by intravenous propranolol alone or quinidine alone. During testing of intravenous propranolol and quinidine in combination, only nonsustained VT with a maximum duration of seven cycles was induced by programmed ventricular stimulation (panel C). Abbreviations are the same as in Figs. 1 and 2.

morphic VT (duration $>30$ seconds, or requiring termination due to hemodynamic collapse) was induced a minimum of three times in each patient during isoproterenol administration. The spontaneous sinus cycle length during the baseline study was $840 \pm 140$ msec (mean \pm S.D.). During continuous intravenous isoproterenol administration, the spontaneous sinus cycle length decreased to $570 \pm 130$ msec $(p<0.05$, paired $t$ test). During continued isoproterenol administration after intravenous administration of propranolol, the spontaneous sinus cycle length increased to $860 \pm 100 \mathrm{msec}(p>0.2$ versus 
the sinus cycle length during the baseline study) (paired $t$ test).

Electrophysiologic testing. Six patients had enhanced automaticity (group A) (Fig. 1), three patients had triggered automaticity (group B) (Fig. 2), and five patients had reentry (group C) (Fig. 3).

Electropharmacologic testing. Overall, 9 of $14 \mathrm{pa}-$ tients $(64 \%)$ had reinduction of VT suppressed by propranolol alone. Three of $14(21 \%)$ patients required propranolol combined with other drug therapy to prevent VT reinduction.

Group A. All six patients with enhanced automaticity had reinduction of VT suppressed by propranolol alone.

Group $B$. None of the three patients with triggered automaticity had VT reinduction suppressed by propranolol alone. One patient had reinduction of VT suppressed by verapamil alone. Two patients had reinduction of VT suppressed by propranolol plus verapamil.

Group C. Three patients with reentry had reinduction of VT suppressed by propranolol alone. One patient had reinduction of VT suppressed by a class Ia drug alone, and one patient had reinduction of VT suppressed by propranolol plus a class Ia drug after failing to respond to a therapeutic serum concentration of the class Ia drug alone.

Follow-up. Follow-up has ranged from 5 to 37 (mean \pm S.D. $=17.9 \pm 10.7)$ months. VT has not recurred spontaneously in any patient. Three patients treated initially with propranolol alone developed refractory congestive heart failure despite preload and afterload therapy. Because of its indirect $\beta$ blocking effects and negligible negative inotropic effects when administered orally, amiodarone was substituted. ${ }^{8}$ None of these three patients had inducible VT after 10 days of oral loading $(800 \mathrm{mg}$ twice a day), and no patient has had a spontaneous recurrence of VT during long-term oral amiodarone administration (200 mg daily).

\section{DISCUSSION}

Isoproterenol is commonly used to facilitate the induction of clinically significant VT when it cannot be induced by standard ventricular programmed stimulation or burst ventricular pacing. ${ }^{1-6}$ As observed in this and earlier studies, many of these patients' VTs are not necessarily exercise-induced. ${ }^{5,6}$ The number of patients requiring isoproterenol to initiate VT make up a small proportion of the total number of patients whose VT is induced in the cardiac electrophysiology laboratory. Of the patients whose VT requires isoproterenol for initiation, a smaller proportion have coronary artery disease when compared with those patients who do not require isoproterenol for VT induction. ${ }^{6}$

The presence of both $\beta_{1}$ and $\beta_{2}$-adrenoreceptors in the human heart has been demonstrated by radioligand studies. ${ }^{9,}{ }^{10}$ Both receptor subtypes appear to be involved in increasing tissue levels of cyclic adenosine monophosphate. ${ }^{11,12}$ Isoproterenol is a nonselective agonist, whereas propranolol is a nonselective antagonist of both $\beta_{1}$ and $\beta_{2}$ receptors. ${ }^{13,} 14$ The potential role that these receptors have in mediating activation of each VT mechanism is discussed separately.

Enhanced automaticity. Spontaneous depolarizations occur most commonly in cells with slow-response action potentials. ${ }^{15,16}$ In isolated cardiac fiber models of spontaneous automaticity, the number of functioning slow channels appears to depend upon cyclic adenosine monophosphate (cAMP). During resting conditions, therefore, there may not be sufficient slow inward current to cause slow-response action potentials to occur. ${ }^{17}$ In this setting, it would be anticipated that $\beta$-receptor stimulation with isoproterenol might cause automatic VT to occur. Conversely, propranolol would be expected to be effective in suppressing such an automatic dysrhythmia. In the present study, all patients with VT due to enhanced automaticity had VT reinduction suppressed by $\beta$-blockade. Sung et al. ${ }^{18}$ have previously reported the failure of verapamil to suppress VT due to catecholamine-sensitive automaticity, and have postulated that this dysrhythmia may not be caused by a slow channel mechanism that is calcium-dependent in humans.

Triggered automaticity. Triggered automaticity caused by delayed afterdepolarizations has been described previously in human tissues. ${ }^{19}$ In experimental models, intracellular calcium overload has been observed to occur during sympathetic stimulation. Subsequent oscillatory release of calcium by the sarcoplasmic reticulum activates a nonselective ion channel utilizing a transient sodium current and modulated by calcium. ${ }^{20-24}$ Of interest, one of the three patients in the present study had triggered automaticity activated by both ventricular extrastimuli and ventricular overdrive pacing. In vitro and in vivo studies have demonstrated a dependence upon a critical range of drive rates or coupling intervals for initiation, a cycle length that varies with the cycle length of the train of stimuli causing initiation, and termination by overdrive pacing, probably due to enhancement of sodium extrusion and membrane hyperpolarization. ${ }^{25}$

Both calcium channel antagonists and $\beta$-receptor blockers have been demonstrated to reduce calcium overload and block the calcium transient. These ac- 
tions result in either reduction of both the action potential and the amplitude of delayed action potentials, or in prevention of delayed afterdepolarization altogether. ${ }^{20,26}$ In the present study, however, the administered intravenous doses of propranolol alone and verapamil alone were insufficient for uniformly suppressing triggered automaticity activated by isoproterenol. In two of the three patients with triggered automaticity, the synergistic effects of $\beta$-adrenoreceptor blockade and calcium channel antagonism appeared to be necessary to suppress reinduction of VT.

Reentry. Reentry is a dynamic process that requires an area of unidirectional impulse block and recirculation of the impulse to its original point of block. ${ }^{27}$ When reentry cannot be initiated during resting conditions, the discrete responses of individual cardiac fibers to isoproterenol stimulation may create the milieu for reentry to occur. Under such conditions, differential shortening of the refractory period of individual fibers caused by isoproterenol provides a course for impulse propogation along fibers that have a shorter refractory period, and blocking in one direction in fibers having a longer refractory period. $^{28,29}$

In the presence of isoproterenol, $\beta$-blockers in concentrations causing $\beta$-blockade alone can reverse isoproterenol's accelerating effects on repolarization. ${ }^{30}$ The inability to reinduce reentrant VT after propranolol administration in three of the five patients in the present study may have been due to this phenomenon. In addition to competitive inhibition of catecholamine binding at $\beta$-receptor sites, $\beta$-blockers have been demonstrated to exhibit direct membranestabilizing action, i.e., "quinidine-like" blockade of the inward sodium current. However, this latter action has been observed only at concentrations that are up to 100 times greater than the clinical concentrations causing $\beta$-blockade. ${ }^{31-34}$

Comparison with previous studies. Few studies have critically evaluated the role of $\beta$-blockade in suppressing VT that requires isoproterenol for its activation. Some studies have utilized intravenous doses of propranolol that may have been too small to effect adequate blockade of isoproterenol during electropharmacologic testing, or have not routinely tested propranolol in consecutive patients. ${ }^{5,6}$ One study ${ }^{35}$ has reported upon the long-term effectiveness of empiric oral $\beta$-blocker therapy for patients requiring isoproterenol for facilitation of VT induction during extrastimulus testing. However, only two of the nine patients in that study had sustained VT induced prior to antiarrhythmic therapy. ${ }^{35}$ To our knowledge, the present study is the first to prospectively evalu- ate the role of $\beta$-blockade in consecutive patients requiring isoproterenol for induction of sustained VT.

Conclusions. In patients requiring isoproterenol for ventricular induction, $\beta$-blockade alone appears to be effective in preventing reinduction of VT caused by enhanced automaticity. A heterogeneous response occurs when the VT mechanisms are triggered automaticity or reentry. The similarity of the sinus cycle lengths measured after treatment with intravenous propranolol treatment during continuous isoproterenol administration, when compared with the sinus cycle lengths measured during the baseline study, suggests that adequate blockade of isoproterenol's $\beta$-agonistic effects should have been achieved with the dose of propranolol administered in this study. The failure of propranolol alone to uniformly suppress all VT activated during isoproterenol administration in this study could have several possible explanations. These include: (1) differences in the total number and the ratio of the subtypes of $\beta$-adrenoreceptors that mediated activation of VT mechanisms in individual patients ${ }^{10,36} ;(2)$ differences in the affinity of these receptors for propranolol and/or isoproterenol when compared with normal human car$\operatorname{diac} \beta$-receptors ${ }^{37}$; and (3) differences in the intrinsic activity of individual patient's $\beta$-receptors in response to isoproterenol and/or propranolol. ${ }^{38}$ Patients who did not respond to intravenously administered propranolol were not retested during long-term oral propranolol administration. Therefore it is possible that the failure of immediate and complete $\beta$-blockade to suppress VT reinduction may not have predicted the results of long-term therapy. ${ }^{39}$ Further investigation will be necessary to substantiate the findings of the present study and to better define the role of $\beta$-adrenoreceptor activation and blockade in human VT mechanisms.

The authors thank Colleen Hoover, BS, Barbara Nagrant, BS, and Judy Jaffke, AS, for their technical assistance in the cardiac electrophysiology laboratory, and Ms. Linda Wylie and Ms. Debbic Laird for their assistance in the preparation of the manuscript.

\section{REFERENCES}

1. Mason JW, Winkle RA. Electrode-catheter arrhythmia induction in the selection and assessment of antiarrhythmic drug therapy for recurrent ventricular tachycardia. Circulation 1978;58:971-85.

2. Wu D, Kou H, Hung .J. Exercise-triggered paroxysmal ventricular tachycardia. Ann Intern Med 1981;95:410-14.

3. Palileo EV, Ashley WW, Swiryn S, et al. Exercise provocable right ventricular outflow tract tachycardia. AM HEART J 1982;104:185-93.

4. Sung RJ, Shen EN, Morady F, Scheinman MM, Hess D, Botvinick EH. Electrophysiology mechanism of exerciseinduced sustained ventricular tachycardia. Am J Cardiol 1983;51:525-30.

5. Reddy CP, Gettes LS. Use of isoproterenol as an aid to elec- 
tric induction of chronic recurrent ventricular tachycardia. Am J Cardiol 1979;44:705-13.

6. Freedman RA, Swerdlow CD, Echt DS, Winkle RA, Soderholm-Difatte V, Mason JA. Facilitation of ventricular tachyarrhythmia induction by isoproterenol. Am J Cardiol 1984; 54:765-70.

7. Zipes DP. Genesis of cardiac arrhythmias: electrophysiological considerations. In: Braunwald E, ed. Heart disease-A textbook of cardiovascular medicine. Philadelphia: WB Saunders Co, 1988:581-620.

8. Mason JW. Amiodarone. N Engl J Med 1987:316:455-66.

9. Stiles GL, Taylor S, Lefkowitz RJ. Human cardiac beta adrenergic receptors: subtype heterogeneity delineated by direct radioligand binding. Life Sci 1983;33:467-73.

10. Brodde $\mathrm{O}$, Schuler $\mathrm{S}$, Kretsch R, et al. Regional distribution of beta adrenoceptors in the human heart: coexistence of functional beta- 1 and beta- 2 adrenoceptors in both atria and ventricles in severe congestive cardiomyopathy. J Cardiovasc Pharmacol 1986;8:1235-42.

11. Brodde O, O'Hara N, Zerkowski HR, Rohm N. Human cardiac beta adrenoceptors: both beta- 1 and beta- 2 adrenoceptors are functionally coupled to the adenylate cyclase in right atrium. J Cardiovasc Pharmacol 1984;6:1184-91.

12. Gille E, Lemoine H, Ehle B, Kaumann AJ. The affinity of (-)-propranolol for beta-1 and beta-2 adrenoceptors in human heart. Differential antagonism of the positive inotropic effects and adenylate cyclase stimulation by (-)-noradrenaline and (-)-adrenalin. Naunyn Schmiedebergs Arch Pharmacol 1985; 331:60-70.

13. Lands AM, Luduena FP, Buzzo HJ. Differentiation of receptors responsive to isoproterenol. Life Sci 1967;6:2241-9.

14. Epstein SE, Braunwald E. Beta-adrenergic receptor blocking drugs. N Engl J Med 1966;275:1106-12, 1175-83.

15. Zipes DP, Besch HR Jr, Watanabe AM. Role of the slow current in cardiac electrophysiology. Circulation 1975;51:761-5.

16. Spear JF. Horowitz LN, Hodess AB, MacVaugh H, Moore EN. Cellular electrophysiology of human myocardial infarction. 1. Abnormalities of cellular activation. Circulation 1979;59:24756.

17. Sperelakis N, Belardinelli L, Vogel SM. Electrophysiological aspects during myocardial ischemia: In: Hayase $S$, Murao $S$, eds. Proceedings of the VIII World Congress of Cardiology. International Congress Series No. 470. Amsterdam: Excerpta Medica, 1978:229-36.

18. Sung RJ, Shapiro WA, Shen EN, Morady F, Davis, J. Effects of verapamil on ventricular tachycardia possibly caused by reentry, automaticity, and triggered activity. $\mathbf{J}$ Clin Invest 1983;72:350-60.

19. Gilmour RF Jr, Heger JJ, Prystowsky EN, Zipes DP. Cellular electrophysiological abnormalities of diseased human ventricular myocardium. Am J Cardiol 1983;51:137-44.

20. Wit AL, Fenoglio JJ Jr, Hordof AJ, Reemtsma K. Ultrastructure and transmembrane potentials of cardiac muscle in the human anterior mitral valve leaflet. Circulation 1979;59:128492

21. Mary-Rabine L, Hordof AJ, Danilo P Jr, Malm JR, Rosen MR
Mechanisms for impulse initiation in isolated human atrial fibers. Circ Res 1980;47:267-77.

22. Aronson RS, Gelles JM. The effect of ouabain, dinitrophenol and lithium on the pacemaker current in sheep cardiac Purkinje fibers. Circ Res 1977;40:517-24.

23. Tsien R, Carpenter DO. Ionic mechanisms of pacemaker activity in cardiac Purkinje fibers. Fed Proc 1978;37:2127-31.

24. Kass $R$, Tsien $R$, Weingart $R$. Ionic basis of transient inward current induced by strophanthidin in cardiac Purkinje fibers. J Physiol (Lond) 1978;281:209-26.

25. Wit AL, Cranefield PF, Gadsby DC. Electrogenic sodium ex trusion can stop triggered activity in the canine coronary sinus. Circ Res 1981;49:1029-42.

26. Tsien RW, Hess P. Fxcitahle tissues. The heart. In: Andreoli TE, ed. Physiology of membrane disorders. New York: Plenum Publishing Co, 1986.

27. Mehra R, Zeiler RH, Grough WB, El Sherif N. Reentrant ventricular arrhythmias in the late myocardial infarction period. IX. Electrophysiologic anatomic correlation of reentrant circuits. Circulation 1983;67:11-24.

28. Kassebaum DG, VanDyke AR. Electrophysiologic effects of isoproterenol on Purkinje fibers of the heart. Circ Res 1966; 19:940-6.

29. Han J, Moe GK. Nonuniform recovery of excitability of ventricular muscle. Circ Res 1964;14:44-60.

30. Giotti A, Ledda F, Mannaioni PF. Effects of noradrenaline and isoprenaline, in combination with alpha and beta receptor blocking substances, on the action potential of cardiac Purkinje fibers. J Physiol 1973;229:99-113.

31. Lucchesi BR, Whitsitt LS, Brown NL. Propranolol (Inderal) in experimentally induced cardiac arrhythmias. Can J Physiol Pharmacol 1966;44:543-7.

32. Morales-Aquilera A, Vaughan-Williams EM. The effects on cardiac muscle of beta-receptor antagonists in relation to their activity as local anaesthetics. Br J Pharmacol 1965;24:332-8.

33. Vaughan-Williams EM. Mode of action of beta receptor antagonists on cardiac muscle. Am J Cardiol 1966;18:399-405.

34. Shinebourne E, White R, Hamer J. A qualitative distinction between the beta receptor blocking and local anesthetic actions of anti arrhythmic agents. Circ Res 1969;24:835-41.

35. Olshansky B, Martins JB. Usefulness of isoproterenol facilitation of ventricular tachycardia induction during extrastim. ulus testing in predicting effective chronic therapy with betaadrenergic blockade. Am J Cardiol 1987;59:573-7.

36. Golf S, Lovstadt R, Hansson V. Beta adrenoceptor density and relative number of beta adrenoceptor subtypes in biopsies from human right atrial, left ventricular, and right ventricular myocardium. Cardiovasc Res 1985;19:636-41.

37. Ariens EJ. The structure-activity relationships of beta-adrenergic drugs and beta-adrenergic blocking drugs. Ann NY Acad Sci 1967;139:606-31.

38. Ariens EJ, van Rossum JM, Simonis AM. Affinity, intrinsic activity and drug interactions. Pharmacol Rev 1957;9:218-36.

39. Raine AEG, Williams EMV. Electrophysiological basis for the contrasting prophylactic efficacy of acute and prolonged betablockade. Br Heart J 1978;40:71-7. 